\title{
Effects of background music on the remembering of filmed events
}

\author{
MARILYN BOLTZ, MATTHEW SCHULKIND, and SUZANNE KANTRA \\ Haverford College, Haverford, Pennsylvania
}

\begin{abstract}
The use of background music within films provides a naturalistic setting in which to investigate certain issues of schematic processing. Here, the relative placement of music was manipulated such that music either accompanied a scene's outcome, and thereby accentuated its affective meaning, or foreshadowed the same scene, and thereby created expectancies about the future course of events. In addition, background music was either congruent or incongruent with the affect of an episode's outcome. When subjects were later asked to recall the series of filmed episodes, results showed that expectancy violations arising from mood-incongruent relations led to better memory in the foreshadowing condition, while mood-congruent relations led to better performance in the accompanying condition. Results from a recognition task further revealed that scenes unavailable for recall could be recognized when cued by background music. These overall findings are discussed in terms of selective-attending processes that are differentially directed as a function of background music.
\end{abstract}

Music can perform several different functions in a culture, but perhaps the most salient of these is its ability to instill different moods and emotions within listeners. Depending on the style of performance (Clynes, 1983; Gabrielsson, 1985, 1989; Shaffer, 1989) and certain structural characteristics of the tune itself (Hevner, 1936; Levi, 1982; Rigg, 1964; Scherer, 1979), some melodies can express positive feelings of lightheartedness, gaity, or relaxation, whereas others can convey more negative feelings of anger, apprehension, or melancholy. Filmmakers have long acknowledged this function of music and have developed various techniques in which music is used to exert certain effects upon a viewing audience. In some cases, music is intended to create expectancies about the activities and outcomes of future scenes; in other instances, music is used to enhance (or reduce) the emotional impact of depicted activities. Although some investigators have examined effects of background music on emotional reactions, the impact of such music on cognitive processing activities remains an unexplored area. The present research provides a preliminary investigation of this issue by considering the potential influence of background music on the remembering of filmed events. This, in turn, provides a naturalistic setting in which to investigate certain issues within the cognitive literature. One issue concerns effects of expectancy confirmation/violation upon

This research was supported by a Faculty Research Grant from Haverford College. The authors thank Brian Knatz for assistance with the manuscript's preparation and W. Jay Dowling, John Sloboda, Portia Maultsby, Margaret Intons-Peterson, and one anonymous reviewer for critical comments on an earlier version of this manuscript. Requests for reprints should be addressed to Marilyn Boltz, Department of Psychology, Haverford College, Haverford, PA 19041 (e-mail: M_BOLTZ@HVRFORD.BITNET). the recall of filmed events and how these may contrast with effects due to scene accentuation. A second goal is to consider the impact of mood (in)congruency on remembering and whether positive and negative affect exert any differential effects upon performance.

\section{The Use of Background Music in Film}

According to various accounts of filmmaking (e.g., Bordwell \& Thompson, 1979; Gianetti, 1982), there are many ways in which dramatic activities can be highlighted through background music. Two of the more common strategies, however, involve foreshadowing and accompaniment. Foreshadowing prepares an audience for a critical, upcoming event by presenting music during a preceding scene where the future course of activities is relatively uncertain. By doing so, the audience is drawn into the film and invited to generate expectancies about what will happen next. For example, the films of Alfred Hitchcock often rely on "solemn, apprehensive" music to induce suspense and alert viewers for an upcoming murder or assault scene. On other occasions, however, filmmakers may "toy" with an audience by creating suspense that eventually proves unwarranted-the director has essentially created a false alarm. Foreshadowing is not limited to scenes laden with negative affect; it can also be used to signal an upcoming positive event.

The second technique of accompaniment varies from foreshadowing in that music does not precede but coincides with the scene of import. Here, the intended effect depends on whether the mood of the music is congruent or incongruent with the mood of the filmed event. In most cases, there is a congruent relationship such that the mood of the music accentuates or enhances the emotional impact of the scene. For example, the music of a death scene may create an air of anguish and distress, and the music 
of a romantic tryst may convey a sense of tenderness. The exception to this convention involves a phenomenom known as ironic contrast. These types of scenes are accompanied by incongruent music whose overall effect is to neutralize, and sometimes satirize, the connotative meaning of the depicted activities. The film Bonnie and Clyde offers some very good illustrations of this technique in that many of the various robbery scenes are accompanied by lively banjo music. This instills a sense of fun into the characters' actions, and the overall significance of their criminal activities is somewhat reduced. Ironic contrast typically relies on one type of mood-incongruency relation-namely, a negative scene paired with positive music; rarely does one find negatively affected music (e.g., sad, angry, fearful) accompanying a pleasant event.

\section{The Potential Impact of Music on Cognitive Behavior}

A question naturally arises: How effective are these techniques for attaining their desired effects? Although very little research has addressed this issue, at least two studies have investigated effects of background music on behavioral affect. In the first of these, Thayer and Levenson (1983) monitored physiological responses while subjects watched a film on industrial accidents. These scenes were accompanied by relaxing "documentary" music, stressful "horror" music, or no music at all. Results indicated that, relative to the control condition, these types of music (i.e, documentary or horror) significantly decreased or increased electrodermal responses, respectively, as a function of their inherent affect. Given that these physiological responses are typically correlated with relaxation and stress, these findings suggest that music can alter the degree of internal arousal.

More recently, Marshall and Cohen (1988) have investigated effects of music upon emotional reactions to a short film clip. This film was originally prepared by Heider and Simmel (1944) and depicts three geometrical figures (a large triangle, a small triangle, and a small circle) moving about a rectangular enclosure. These figures are often associated with certain personality traits, and the goal of this research was to determine whether affective impressions change as a function of background music. Results supported this notion and revealed that ratings of the film's "characters" on the semantic differential scales were directly influenced by the music's affect. For example, the large triangle was perceived as more agitated and aggressive when the accompanying music was louder and more active. Marshall and Cohen (1988) suggest that the underlying mood dimensions of music serve to direct attending toward the activity level of characters as well as their apparent strength and "goodness." In this sense, then, music can accentuate various qualities of visual activities and thereby enhance their perceptual salience.

The purpose of the present experiment was to extend this research by considering the impact of background music upon memory performance. Given that music draws attention to a scene and influences the emotional reactions of an audience, one might expect a corollary effect on memory such that scenes with background music are better remembered than are those with no music. On the other hand, the memorability of scenes may depend on the relative placement of music and relationships of mood congruence. Foreshadowing and accompaniment rely on the inherent mood of music to achieve different psychological goals. These, in turn, may involve different attentional processes that subsequently affect memory performance.

First, consider foreshadowing music. Through its structural arrangement of thythm, tempo, and relative pitch height and distance, music is able to communicate different moods to a listener (Hevner, 1936; Levi, 1982; Rigg, 1964; Scherer, 1979). By presenting such music before a critical scene, the filmmaker thereby encourages the audience to actively extrapolate a future scheme of events that is congruent with the implied mood. These expectancies can then be resolved in one of two ways. If the ensuing scene is congruent with the mood of the music, expectancies are confirmed and the viewer's extrapolation matches the episode's outcome. However, if the final scheme of events is incongruent with the affective meaning of music, then expectancy violations occur and the ending becomes a "surprise." The question addressed here is: Which scenes are better remembered-those that conform to schematic expectancies or those that violate expectancies? Although the literature reveals conflicting answers to this question (Bower, 1976; Kintsch \& van Dijk, 1978; cf. Bobrow \& Norman, 1975; Friedman, 1979), most studies have shown that expectancy violations are more salient in memory (e.g., Bower, Black, \& Turner, 1979; Graesser, Woll, Kowalski, \& Smith, 1980; Maki, 1990; Nakamura, Graesser, Zimmerman, \& Riha, 1985; Smith \& Graesser, 1981). For example, Smith and Graesser (1981) presented passages to subjects in which script actions had been prerated for their degree of typicality. These scripts depicted a variety of everyday activities that were highly routine and familiar to all subjects. When subjects were later asked to recall these stories, events containing atypical actions and/or objects were found to yield significantly higher recall and recognition performance than events conforming to the underlying script. Similar findings have also been reported in the area of person memory. Behaviors that are inconsistent with trait expectations are much better remembered than are those that are consistent with one's preconceived schema (e.g., Belmore \& Hubbard, 1987; Crocker, Hannah, \& Weber, 1983; Hastie, 1980; Hastie \& Kumar, 1979; Srull, 1981; Srull \& Wyer, 1989).

Several different theoretical accounts have been offered to explain these findings. One appeals to attentional activities and suggests that schema-inconsistent information simply receives more attention than does schema-consistent information (Bobrow \& Norman, 1975; Friedman, 1979). People try to make sense of script anomalies and devote more processing toward their meaningfulness. A second explanation is based on memory processes. This approach, termed the schema-copy-plus-tag hypothesis (Graesser, 1981; Smith \& Graesser, 1981), claims that episodic tags 
for unexpected events are attached to the generic schema that is already stored in memory. These tags are highly accessible in memory because they "stand out" from schema-consistent information that has previously been represented as default knowledge. This view is not necessarily inconsistent with the attentional explanation, but it suggests how unexpected information remains salient in memory after its initial input.

One purpose of the present experiment was to determine whether these effects generalize to the use of foreshadowing music. Relative to conditions of expectancy confirmation, episodes resulting in a surprise ending may be better remembered because they capture one's attention and yield a more salient memory code. On the other hand, foreshadowing creates a different kind of an expectancy that has not been well investigated in the literature. That is, most studies addressing the expectancy concept have manipulated the typicality of objects or action units relative to a well-defined behavioral routine (e.g., going to a restaurant, visiting the doctor or dentist). In these situations, very little mental extrapolation is required by a subject, because the script specifies exactly what should happen next. In addition, any violation of expectancies will stand out and be quite salient, because these atypical events directly contradict the script's prescribed course. This set of circumstances may contrast with those arising from the use of background music in filmed events. In particular, at least two fundamental differences seem apparent. First, background music occurs during a preceding scene where the future course of events is often relatively uncertain. Although the preceding context will, to some extent, define a class of permissable actions that could immediately follow, there is nevertheless some uncertainty about which particular direction the upcoming sequence of action will follow. The mood of the music will presumably imply the connotative meaning of the upcoming scene, but, again, the degree of certainty associated with this type of expectancy is still much less than that deriving from a well-defined script. Thus, when the viewer's expectancy is subsequently violated, the unexpected outcome may be relatively less surprising and therefore less salient in perception and memory.

A second difference involves the amount of mental effort required by subjects. In contrast to a well-defined script where expectancies span over lower level action units and are prescribed by the script itself, foreshadowing music encourages a more global expectancy where a much longer sequence of activities must be extrapolated. This requires more imaginative effort on the part of the subject where the motivation of characters and the meaning of their actions must be construed. A study by Spiro (1980), in fact, has addressed this sort of situation by inducing expectancies about the future outcome of a couple's engagement. Although an immediate-recall task revealed no differences in performance as a function of expectancy confirmation/violation, subsequent tests after varying lengths of time indicated that expectancy violations led to more constructive memory errors. These find- ings demonstrate that expectancy violations can sometimes impair memory performance and may therefore depend on other factors, such as the ones outlined here.

A second purpose of this experiment was to examine effects of accompanying music upon the remembering of visual events. This film technique involves cognitive processes that are somewhat different from those of foreshadowing music in that viewers are not required to extrapolate the future course of events. Instead, music is intended to act as an accentuation device and to influence the emotional impact of a scene. Although accompanying music may therefore improve memorability, this effect should depend on mood congruency. In situations where the mood of the music corresponds to the affective meaning of the scene, memory should be quite high for at least two reasons. First, as Marshall and Cohen (1988) have suggested, the music's mood should direct attending toward certain underlying dimensions of a scene-namely, the degree of activity and its evaluative meaning. This not only enhances the emotional impact of a scene but may also allow the viewer to make certain inferences about the thoughts and feelings of the main characters and the motivations of their actions. These inferences may be ones of bridging (Clark, 1977; Clark \& Haviland, 1977; Keenan, Baillet, \& Brown, 1984; McKoon \& Ratcliff, 1986; Singer, Revlin, \& Halldorson, 1990) or elaboration (Graesser \& Clark, 1985; Long, Golding, Graesser, \& Clark, 1990; McKoon \& Ratcliff, 1981, 1986), but, in either case, they serve to establish a more coherent and integrated memorial representation.

Mood incongruency, on the other hand, is predicted to decrease the memorability of a scene. Although this factor is sometimes used for ironic contrast, the overall intent is to reduce both the emotional impact and significance of a scene. The music's mood may act to misguide attending toward irrelevant activities such that the underlying goal of behavior and event relationships become obscured. The scene may therefore appear to lack coherence and meaning, which in turn affects subsequent remembering. Such effects have been noted in the previous literature in which schema-inconsistent relations have been found to impair the remembering of visual scenes (Biederman, 1972, 1981; Loftus, 1972; Loftus \& Bell, 1975) and social interactions (Bear \& Hodun, 1975; Picek, Sherman, \& Shiffrin, 1975).

To summarize, the present research was designed to examine certain principles of schematic processing through manipulations of background music within filmed events. Specifically, subjects were asked to view a series of episodes extracted from various televised programs. Although the overall scheme of a story was lacking, each episode could be considered an independent unit (Black \& Bower, 1979; Glenn, 1978; Haberlandt, 1980; Mandler, 1978; Mandler \& Johnson, 1977; Thorndyke, 1977) in which the sequence of activities was oriented toward a given goal that was eventually resolved. In half of the scenes, the mood of the music was matched to the positive or negative mood implied by the episode's outcome; 
in the remaining half, this relationship was an incongruent one. The relative placement of the music was also manipulated by presenting the same series of episodes to three different groups of subjects. For the first group, background music always foreshadowed the episode's outcome. For the second group, this same music accompanied the scene's resolution. For the third group of subjects, which functioned as a control group, no music was presented at all. Following the viewing of these filmed events, subjects were then asked to perform a series of incidental memory tasks that were carefully ordered to minimize any carryover effects. The first was a free-recall task in which the subjects were asked to provide a written recall of the various episodes they had just viewed. The goal here was to determine whether subsequent remembering is differentially influenced by both the placement of music and relationships of mood congruency. The latter two tasks were designed to assess the memorability of background music and the extent to which music is integrated into the memory of a visual scene. One was a tune-recognition task and required the subjects to discriminate "old" melodies from "new," distractor ones. Although numerous studies have investigated recall and recognition memory for musical events (for reviews, see Dowling \& Harwood, 1986; Handel, 1989; Sloboda, 1985), very little, if any, research has considered whether music is incidentally encoded into memory. With respect to filmmaking, this would be a reasonable phenomenon if music does, in fact, influence the remembering of filmed episodes. A second question, however, is whether or not background music can be accessed independently of the scene it has highlighted. Alternatively, the tune may be integrated into the memorial representation of its respective scene such that a viewer is only able to recognize the tune in the presence of the scene itself. The tunerecognition task assessed the independence issue by examining whether or not recognition performance was significantly above chance when tunes were presented in the absence of their original film context. The final task of cued-scene recognition, on the other hand, was designed to address the integration issue and to determine whether or not music provides an effective cue for remembering its respective scene.

\section{METHOD}

\section{Design and Subjects}

The design was a $2 \times 2 \times 2 \times 2$ mixed factorial. The subjects viewed a series of filmed episodes in which the mood of background music was either congruent or incongruent with the positive or negative affect associated with an episode's outcome. Counterbalancing of mood congruency and the placement of music relative to an episode's outcome were the two between-subjects factors. For one group, music always foreshadowed an episode's ending. For a second group, music always accompanied the final outcome. A control group was also included in which the subjects viewed the same series of filmed episodes but with no background music.

Sixty students from an introductory psychology course at Haverford College participated as subjects in the experiment in return for course credit. The subjects were randomly assigned to one of the between-subjects conditions.

\section{Stimulus Materials}

The filmed material used in this experiment was based on four feature-length movies and several 30-min programs recorded from network television: ${ }^{1}$ Alfred Hitchcock Presents, The Hitchhiker, and Shortstories. Twenty different clips, each approximately 3-4 min in duration, were then extracted from these films. Each film clip could be considered an independent "episode" from its respective story, in that it represented an event with a distinct beginning and end that was further reinforced by shifts toward new scene settings. Although all episodes contained a certain degree of suspense in which the final outcome could not be reliably predicted from the preceding activities, half resolved in a positive "happy" ending, and the other half resolved in a negative, sometimes tragic, ending.

A series of 47 tunes were also recorded from these same television programs. All were approximately $20-30 \mathrm{sec}$ in duration, of equal amplitude, and relatively "simple" melodies performed with a single instrument (e.g., electronic synthesizer, piano, flute, oboe) and devoid of any lyrics or overlapping dialogue. Relying on criterion established in the previous literature (Hevner, 1936; Levi, 1982; Rigg, 1964; Scherer, 1979), the structural characteristics of these tunes (i.e., overall tempo, mode, pitch level, and contour) were used to match melodies for their type of affect. Approximately half of the melodies displayed properties associated with positive affect-namely, a rapid tempo, major mode, and an overall high level of pitch with many changes in pitch direction. The remaining melodies were considered to express negative affect, in that they displayed a relatively slow tempo, minor mode, and a low level of pitch with few changes in pitch contour.

To validate the affect and familiarity of these stimuli, a series of independent rating tasks were then conducted. In the first rating task, the 20 film clips were recorded onto videotape and presented to a group of 6 subjects. Each film clip lacked background music but contained dialogue among the film's characters. After viewing each episode, the subjects were asked to rate its familiarity on a 7-point scale, where values ranged from $1=$ very familiar to $7=$ very unfamiliar. The subjects were also asked to rate the affect of each episode's outcome with a set of 13 paired antonyms. The selection of these adjectives, listed in Appendix A, were based on the multidimensional scaling model reported by Russell (1980) and reflected the dimensions of pleasantness/unpleasantness and activity/inactivity. To assess the intensity of each antonymic pair, the two adjectives were represented on an 11-point Likert scale, ranging from $-5 \ldots-1$ to 0 to $+1 \ldots+5$. During a $1-$ min response period following each filmed episode, the subjects were instructed to circle a value on each of the 13 scales and, if a particular pair of adjectives was deemed nonapplicable to that episode's ending, they were told to circle the value of 0 .

A similar procedure was also used for the rating of tunes. A second group of 6 subjects heard the series of 47 tunes and, after each, rated the melody for its affect and degree of familiarity.

The data from these two tasks were then used to construct the set of experimental stimuli. After eliminating the tunes and episodes familiar to some subjects, the pattern of mean affect ratings was determined for each of the remainder. Those tunes and episodes sharing a highly similar profile of mean ratings were paired and labeled as mood congruent. This yielded a set of 16 different tunes and 16 different episodes, where half of the episodes displayed a positive outcome and half a negative outcome. The mean ratings for these tunes and episodes were then compared with one another to determine the pairings that were highly dissimilar in overall affect. Thus, each episode was paired with two tunes, one that was highly congruent in mood and one that was highly incongruent. There were no instances in which a particular tune was paired with its original televised episode. An independent set of three naive judges confirmed the validity of these pairings before the final taping of all experimental conditions. Appendix B presents a brief description of all episodes along with their primary mood associations. 
In addition to variations in mood congruency and the affect of episode endings, the relative placement of background music was also manipulated. The 16 film episodes were first randomized into a given order and videotaped such that there was a 10 -sec blank screen between each successive episode In the accompanying condition, one of the paired tunes for each episode was then dubbed in during the climatic closing scene, which typically was either the final or the penultimate scene in the episode. Half of the episodes were accompanied by mood-congruent music and half by incongruent music, and when this variable was crossed with the affect of episode endings, this resulted in four instances of the following pairs: positive music-positive outcome, negative music-negatıve outcome, positive music-negative outcome, and negative musicpositive outcome. A second accompanying condition was also prepared where the mood congruency of each tune-episode pair was reversed: pairs that were congruent in the previous condition were now incongruent, and vice versa. Two such tapes were also constructed for the foreshadowing conditions. Here, however, the tune paired with each episode did not coincide with the climatic outcome but, instead, the tune's ending preceded the target scene by approximately $10-15 \mathrm{sec}$. The music therefore occurred during an immediately preceding scene in which the future course of events was relatively uncertain and ambiguous in affect. The amplitude of tunes was adjusted such that it was clearly audible but did not "drown out" any accompanying dialogue. Lastly, the tape for the control condition displayed the same ordering of scenes but without any background music.

Materials for the tune-recognition task. For this phase of the experiment, 32 randomly ordered tunes were recorded onto cassette tape with a 7-sec silence period between each successive tune Half of these were "new," distractor tunes; the remaining half were "old," in that they had been paired with a given film episode within the previous phase of the experiment. Each new tune was matched with a given old tune for its overall affect; across all tunes, total duration and amplitude were kept relatively constant.

Materials for the cued-scene-recognition task. For this task, each of the 16 old tunes were recorded onto videotape in a randomized order. Each tune was accompanied by a blank screen, but immediately following this, six different "still" scenes were presented. Three of these scenes were from the same filmed episode as the tune itself. One, in fact, had originally co-occurred with this tune, whereas a second (same-relevant) had either immediately preceded or followed the tune. Thus, these corresponded to the scenes in which foreshadowing and accompanying music had originally occurred. The third (same-irrelevant) was a scene that had also occurred near the episode's end but had never been paired with music. The three remaining scenes were from the second film episode in which a particular tune could be paired (i.e., depending on the counterbalancing of mood congruency) and were taken from analogous locations within the episode. Given that the subjects heard only a particular tune paired with one episode, these were all considered to be different.

On each of the 16 trials, a 3 -sec period of silence followed each tune and $4 \mathrm{sec}$ of blank screen separated each successive still scene. At the end of the six still scenes, a $10-\mathrm{sec}$ response period was provided before the onset of the next tune.

\section{Apparatus}

Programs from network television were recorded with a Hitachi VT-73AY videocassette recorder interfaced with a RCA XL100 television monitor. A Panasonic AG-1950 Editing System was used for tape editing and the construction of stimulus materials.

During the actual experiment, the subjects viewed the series of filmed episodes on a 19-in. Toshiba C990 television monitor inter faced with a Sharp XA205 videocassette player. An Aiwa CAW75 cassette player was also used for the recording and dubbing of tunes and their subsequent playback during the tune-recognition phase of the experiment

\section{Procedure}

The subjects were informed that their task was to watch a series of filmed episodes and, after each, to estımate how much time seemed to have transpired between the episode's beginning and end. They were also asked to indicate whether or not they had previously seen any of the episodes they had just viewed. Immediately following the presentation of a given film version, the subjects were then asked to perform a set of unexpected memory tasks. These were administered in the following order to minimize any carryover effects across tasks

Recall task. In this first task, all subjects were asked to provide a written recall for each of the filmed episodes. They were told they could recall these in any order they pleased but to indicate as much detail as possible concerning the episodes' actions, characters, and final outcome The subjects were given $20 \mathrm{~min}$ to complete this task

Tune recognition. Following the recall task, the subjects in the experimental conditions were presented with a randomized series of 32 tunes During a 7-sec response period, they were asked to decide whether each was old or new by circling the appropriate judgment on a response sheet This task took approxımately $15 \mathrm{~min}$ to complete

Cued-scene recognition. In this final task of the experıment, the subjects heard each of the 16 old tunes accompanied by six stıll scenes. On each trial, their task was to decide which scene had ong1nally been paired with that particular melody. Judgments were indicated on a response sheet and, overall, this task took approximately $15 \mathrm{~min}$ to complete

The subjects were tested in small groups of 2-4 individuals and asked to remove their watches before the onset of the experimental session

\section{RESULTS}

Those subjects indicating familiarity with any of the filmed episodes were eliminated from the data analysis. The time estimation data were collected for another series of experiments and are presented elsewhere (Boltz, 1991). Data from the various memory tasks were analyzed separately through a series of analyses of variance. Given that counterbalance order and the various film episodes exerted nonsignificant effects, mean performance is collapsed over these two factors. The results for each task are addressed in turn.

\section{Overall Recall Performance}

For each subject, response protocols were scored on an all-or-none basis for the percentage of episodes (out of a total of 16) that were correctly recalled. Most subjects provided a two- to three-sentence description for each episode, and these were evaluated by three naive judges, relative to the outlines in Appendix B. Each protocol was scored by all judges, and unanimous agreement was required for a given episode to be categorized as "correct." Since the subjects never intruded a novel scene into their written protocols, all errors within this analysis are strictly due to scene omission.

The most important finding to emerge from the overall analysis of variance is a significant interaction between mood congruency and the relative placement of music $\left[F(1,66)=10.83, M S_{c}=329.57, p<.0001\right]$. As seen in Figure 1, music accompanying an episode's outcome led to higher recall when the mood of the music and scene 


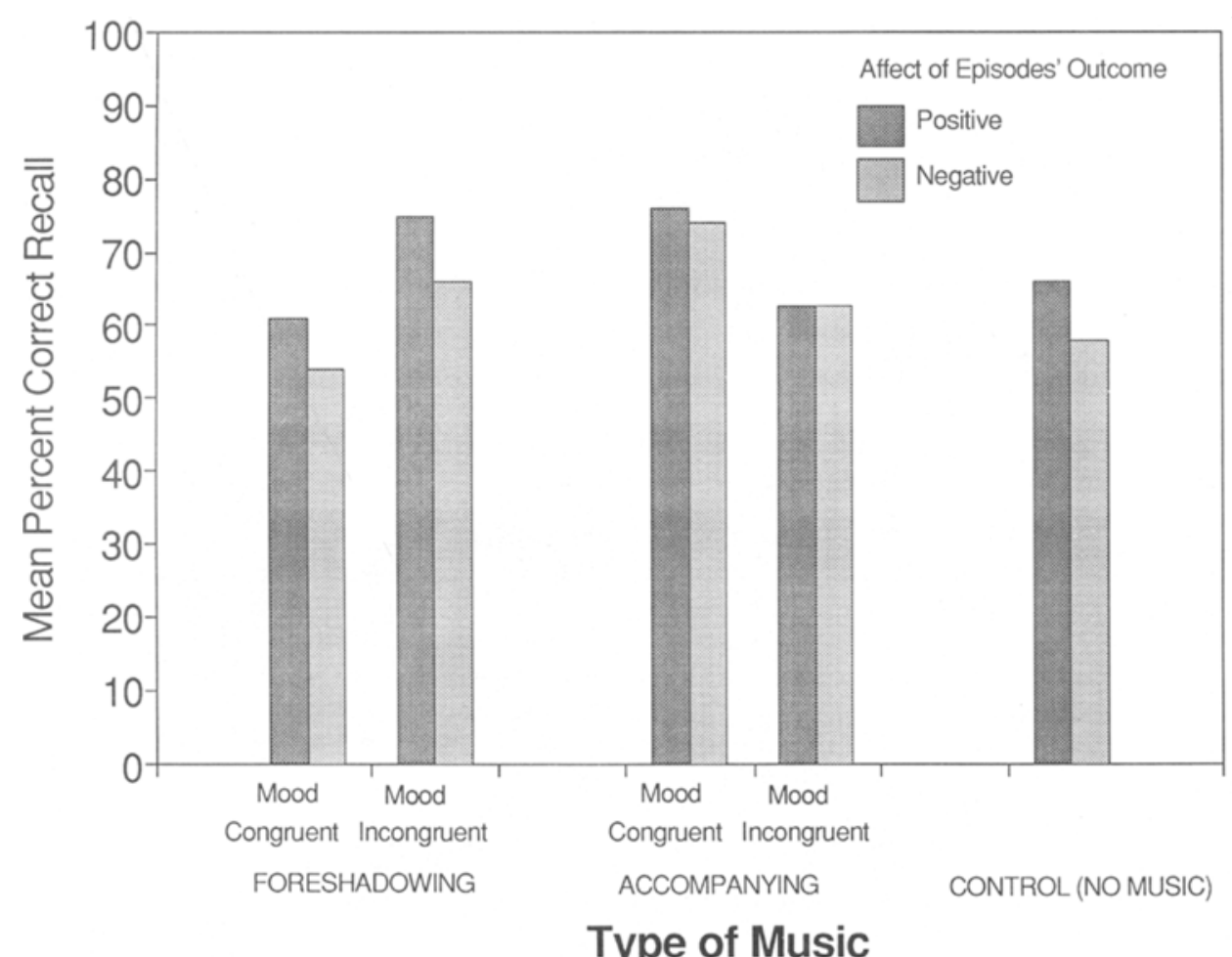

Figure 1. Mean percent correct recall of filmed episodes as a function of music placement, mood congruency, and affect associated with a scene's outcome.

were congruent with one another. Conversely, moodincongruent relations significantly lowered performance to a level that was comparable to that of the control condition in which no music occurred at all. These effects were relatively robust ones that occurred for 19 of the 24 subjects in the accompanying condition. Foreshadowing music, on the other hand, revealed an opposite pattern of results. Here, expectancy violations arising from moodincongruent relations were significantly more memorable than were mood-congruent episodes in which viewers' expectancies were confirmed. Performance in the latter condition was, in fact, indistinguishable from that of the control group. This effect also appears to be a reliable one that was revealed by 18 of the 24 subjects in this condition. The relative differences in performance as a function of music placement and mood congruency were all confirmed by a set of Bonferroni post hoc comparisons (Dunn, 1961) in which $p$ level was set at .01.

The second notable finding from this analysis is a significant three-way interaction between music placement, mood congruency, and the particular affect associated with an episode's outcome $\left[F(2,66)=5.34, M S_{c}=484.66\right.$, $p<.008]$. In the accompanying condition of Figure 1 , notice that mood-congruent relations yielded higher memory recall for scenes that were associated with either positive or negative affect. Although there was a slight tendency for positively affected scenes to be better recalled than negative ones, this difference was a nonsignificant one. In the foreshadowing condition, however, overall performance was significantly higher with scenes resolving to a positive outcome. Although expectancy violations led to greater memorability across both conditions of affect, this effect was attenuated with scenes depicting a negative ending. Bonferroni comparisons confirmed these differences with $p<.01$.

\section{Tune Recognition}

The incidental memory for background music was evaluated through three types of analyses. The first examined mean hit rate across all experimental conditions. As seen in Table 1, there were no significant effects due to the experimental manipulations $(F<1.0)$, and recognition accuracy was, in fact, near chance performance.

A second analysis examined mean false-recognition rate and showed that neither mood congruency nor music placement exerted a significant effect upon performance. There was, however, a main effect for the overall affect of melodies $\left[F(1,44)=14.38, M S_{\mathrm{e}}=.0539, p<.0005\right]$. As seen in Table 1, tunes expressing negative affect produced a higher false-recognition rate than those communicating positive affect.

Given the latter finding, a $d^{\prime}$ analysis was then conducted to obtain a discrimination measure that corrects for guessing and response-bias effects. The new distractor tunes prerated as expressing positive affect were assigned to the two conditions in which positive music origi- 
Table 1

Mean Performance in the Tune-Recognition Task as a Function of Music Placement, Mood Congruency, and Affect Associated with an Episode's Outcome

\begin{tabular}{|c|c|c|c|c|}
\hline & \multicolumn{2}{|c|}{ Mood Congruent } & \multicolumn{2}{|c|}{ Mood Incongruent } \\
\hline & $\begin{array}{l}\text { Positive Music- } \\
\text { Positive Outcome }\end{array}$ & $\begin{array}{l}\text { Negative Music- } \\
\text { Negative Outcome }\end{array}$ & $\begin{array}{l}\text { Negative Music- } \\
\text { Positive Outcome }\end{array}$ & $\begin{array}{l}\text { Positive Music- } \\
\text { Negative Outcome }\end{array}$ \\
\hline \multicolumn{5}{|c|}{ Foreshadowing Music } \\
\hline Hit Rate & .58 & .57 & .55 & .56 \\
\hline False Recognitions & .27 & .41 & .41 & .27 \\
\hline$d^{\prime}$ & .95 & .49 & .43 & .91 \\
\hline \multicolumn{5}{|c|}{ Accompanying Music } \\
\hline Hit Rate & .58 & .50 & .60 & .53 \\
\hline False Recognitions & .23 & .37 & .37 & .23 \\
\hline$d^{\prime}$ & 1.28 & .28 & .51 & 1.41 \\
\hline
\end{tabular}

nally occurred, and the tunes rated as "negative" were assigned to conditions in which negative music originally occurred. Mean $d^{\prime}$ values were then determined through a procedure reported by Hochhaus (1972) and are depicted in Table 1. The results of this analysis converged with the false-recognition data and revealed a significant main effect for a tune's affect $\left[F(1,44)=16.24, M S_{\mathrm{e}}=1.491\right.$, $p<.0002$ ]. Tunes associated with positive affect were better discriminated than those associated with negative affect and, as before, this effect generalized across all experimental conditions of mood congruency and music placement. Relative to the foreshadowing condition, there was a tendency for positive-affect tunes to be better discriminated in the accompanying condition, but this effect failed to attain significance $(p<.08)$.

\section{Cued-Scene Recognition}

In this task, the subjects were presented with a tune and asked to recognize which of six scenes had originally cooccurred with the melody. The chance probability of selecting the correct scene was therefore equal to .17 . Two of the distractor scenes were from the same episode as a given melody, one associated with a scene that had never been accompanied by music (same-irrelevant) and the other associated with the scene that had been foreshadowed (or accompanied) in the second condition of music placement (same-relevant). The probability of selecting each of these scenes at chance was also .17. The remaining three scenes were from an entirely different episode as the melody (different), and the chance probability of their selection was therefore equal to .50 . To determine how well the subjects were able to perform this task, two types of analyses were conducted. The first examined mean hit rate across all conditions; the second considered mean false-recognition rate for each type of distractor. These two measures, depicted in Table 2, are each addressed in turn.

The overall analysis of variance for hit rate revealed a significant interaction for music placement, mood congruency, and affect associated with an event's outcome $\left[F(1,44)=8.49, M S_{\mathrm{e}}=327.41, p<.009\right]$. Table 2 shows that the source for this interaction lies in the accompanying condition. Notice that, in the mood-congruent conditions, recognition performance was significantly above chance and that scenes reinforced with positive music were better recognized than those reinforced with negative music. In the mood-incongruent conditions, however, this pattern was altered. Although positive music was

Table 2

Mean Performance in the Cued-Scene-Recognition Task as a Function of Music Placement, Mond Congruency, and Affect Associated with an Episode's Outcome

\begin{tabular}{|c|c|c|c|c|c|}
\hline & \multirow[b]{2}{*}{$\begin{array}{c}\text { Probability of } \\
\text { Chance Performance }\end{array}$} & \multicolumn{2}{|c|}{ Mood Congruent } & \multicolumn{2}{|c|}{ Mood Incongruent } \\
\hline & & $\begin{array}{l}\text { Positive Music- } \\
\text { Positive Outcome }\end{array}$ & $\begin{array}{l}\text { Negative Music- } \\
\text { Negative Outcome }\end{array}$ & $\begin{array}{l}\text { Negative Music- } \\
\text { Positive Outcome }\end{array}$ & $\begin{array}{l}\text { Positive Music- } \\
\text { Negative Outcome }\end{array}$ \\
\hline \multicolumn{6}{|c|}{ Foreshadowing Music } \\
\hline $\begin{array}{l}\text { Hit Rate } \\
\text { False Recognitions }\end{array}$ & .17 & .31 & .30 & .31 & .29 \\
\hline Same-Relevant Scenes & .17 & .21 & .20 & .19 & .22 \\
\hline Same-Irrelevant Scenes & .17 & .14 & .11 & .12 & .11 \\
\hline Different Scenes & .50 & .34 & .39 & .38 & .38 \\
\hline \multicolumn{6}{|c|}{ Accompanying Music } \\
\hline $\begin{array}{l}\text { Hit Rate } \\
\text { False Recognitions }\end{array}$ & .17 & .38 & .30 & .15 & .38 \\
\hline Same-Relevant Scenes & .17 & .15 & .17 & .08 & 14 \\
\hline Same-Irrelevant Scenes & .17 & .14 & 19 & .09 & .15 \\
\hline Different Scenes & .50 & .33 & .34 & .68 & .33 \\
\hline
\end{tabular}


an effective cue for recognizing scenes with a negative outcome, the reverse pairing led to a level of performance that was indistinguishable from chance (all Bonferroni post hocs, $p<.01$ ). These overall effects of mood congruency and affect of an episode's outcome did not generalize to the foreshadowing condition. Here, recognition performance was significantly higher than chance in all conditions $(p<.01)$, and these effects did not depend on the affect of a melody relative to that of its respective scene.

Next, consider the false-recognition data depicted in Table 2 . These results suggest that false recognitions vary across the conditions of music placement, mood congruency, and affect of an episode's outcome, and the overall analysis of variance confirms that this interaction was, in fact, significant $\left[F(2,44)=5.68, M S_{\mathrm{e}}=291.73, p<\right.$ $.006]$. The simplest way to understand these findings is to examine performance within each condition of music placement. First, consider the foreshadowing condition. For each of the three distractor types, there were no differences as a function of mood congruency or the relative affect of an episode's outcome-all conditions yielded comparable performance within each distractor type. An examination of false-recognition rates relative to levels of chance performance, however, shows that there were differences between the three distractors. Although same-irrelevant and different scenes yielded error rates that were below chance, the false-recognition rate for same-relevant scenes was above chance. Thus, when the subjects made errors in this condition, they were more likely to falsely recognize scenes that were foreshadowed (i.e., corresponding to expectancy outcomes) than scenes from an entirely different episode or scenes from the same episode but unrelated to the music. In contrast, the accompanying-music condition revealed a somewhat different pattern of results. Here, the mean false-recognition rate for different scenes was also quite low across all conditions, but the probability of falsely recognizing a same-relevant scene was equal to that of a same-irrelevant scene. The one exception occurred when negative music accompanied a scene with a positive outcome. In this condition, the false-recognition rate for same-irrelevant and same-relevant scenes was significantly lower $(p<.01)$ than that in other conditions, while the probability of falsely recognizing a different scene was significantly higher $(p<.01)$.

\section{DISCUSSION}

The results of this research demonstrate that background music can influence the remembering of filmed events. Depending on the mood congruency and placement of music relative to a critical scene, music can enhance subsequent recall relative to situations where no music occurs at all. In addition, mood (in)congruency appears to affect retrieval accessibility in that scenes that were previously unavailable for recall could be recognized when cued by background music. Lastly, all measures of memory performance within this experiment reveal asymmetrical effects due to the mood of a tune or scene such that positive events show consistent superiority over negative events. Each of these findings relates to more general issues within the cognitive literature. Each is addressed in turn.

First, consider the effects of music within the recall task. The most notable finding is an interaction between music placement and mood congruency such that foreshadowing and accompanying music exert differential effects upon the memorability of filmed events. In the case of accompaniment, music directly coincides with the scene's outcome to act as an accentuation device and highlight attending toward the respective scene. Results, however, indicate that the mere presence of music does not improve memory. It is only when the mood of the music is congruent with the mood of the scene's outcome that recall is significantly enhanced. Incongruent music, on the other hand, yields performance levels comparable to that found with a control condition in which no music occurs at all. These findings then suggest that effects of accompaniment involve factors beyond the attentional heightening of music.

One such factor has been previously suggested by Marshall and Cohen (1988) and involves selective-attention mechanisms. According to this account, the underlying mood dimensions of music direct attending toward corresponding aspects of visual behavior. These mood dimensions are typically defined in terms of pleasantness/ unpleasantness, degree of activity level, and intensity of the emotion (e.g., Osgood, 1969; Plutchik, 1962; Russell, 1980; Schlosberg, 1952). Thus, consider the case where a "happy" tune coincides with the positive outcome of an episode. Given that happiness is musically expressed through wide, rapid pitch fluctuations, "bouncy" rhythms, and an overall fast tempo (Hevner, 1936; Levi, 1982; Rigg, 1964; Scherer, 1979), these factors may guide attending toward corresponding attributes of visual behavior. This not only focuses the viewer upon those actions and behaviors that are congruent with the connotative meaning of the scene, but it also acts to accentuate and reinforce the emotional impact of the scene itself. Some validity is granted to this idea in that the structural correlates of different moods are remarkably invariant across music, speech (Cosmides, 1983; Williams \& Stevens, 1979), facial expressions (Ekman, 1978; Ekman \& Friesen, 1975), and walking gaits (Montepare, Goldstein, \& Clausen, 1987; Sloman, Berridge, Homatidis, Hunter, \& Duck, 1982). Thus, the underlying mood dimensions of a scene may be "captured" by the music's affect such that selective attending is synchronously driven. This idea is supported by the work of Spelke (1979), who finds that infants devote more attending to films accompanied by an appropriate soundtrack than to films accompanied by an inappropriate one. In addition, the infants' patterns of gaze tend to focus on those visual activities that correspond to the tempo of the accompanying music.

The direction of selective attending that is guided by background music may also have a corollary effect upon viewers by promoting certain types of inferences. That is, if music directs attending toward relevant patterns of action, then a viewer may be drawn into the film such 
that he/she more closely identifies with the main character. This, in turn, allows a viewer to both integrate and elaborate upon the surrounding set of activities such that relations among the character's motivations and patterns of behavior become more clear. These types of inferences are typically referred to as ones of coherence (Black, Galambos, \& Read, 1984; Kintsch, 1974; Kintsch \& van Dijk, 1978) and elaboration (Graesser \& Clark, 1985; Long, Golding, Graesser, \& Clark, 1990; McKoon \& Ratcliff, 1981, 1986) and have been shown to markedly improve memory performance. In the present experiment, there was an attempt to identify such inferences, but, given the brevity of the recall protocols, this attempt was subsequently abandoned. Future investigations, however, may address this potential influence of background music by decreasing the number of presented scenes and/or by testing memory after longer retention intervals.

In sum, the effects of accompanying music are suggested to involve attentional mechanisms. The underlying mood of a tune may direct attending toward corresponding patterns of activity that are central to the episode's "theme." This may also highlight important relations among the story's elements that are then elaborated upon through the connotative overtones of the music. The resulting memory code is therefore a very coherent one whose accessibility may be enhanced through the distinctiveness of its emotional charge. It is noteworthy that mood-incongruent music did not impair performance relative to the control condition in which no music occurred at all. This suggests that viewers in this situation simply did not use the music for encoding the filmed event. Given the mood incongruency, the background music is seemingly irrelevant to the visual scene and fails to direct one toward any comparable sets of structural or semantic relations. Although data from the scene-recognition task indicates that such music is encoded into memory, it fails to exert any facilitating effects through attentional or inferential activities.

The second major finding within this experiment concerns the influence of foreshadowing music upon memory performance. In contrast to the accompanying condition, mood-incongruent relations yield superior memorability over mood congruent ones. Given the relative timing of music, these effects reveal that expectancy violations are better remembered than are scenes conforming to a viewer's expectancies. Such findings are consistent with the previous literature on schematic processing and trait impressions (e.g., Bower, Black, \& Turner, 1979; Smith \& Graesser, 1981; Hastie, 1980; Maki, 1990; Srull, 1981) and further extend this work by demonstrating the generalizability of the expectancy concept. Most manipulations of expectancies have involved actions and objects relative to a well-defined script, whereas expectancies within the present experiment were induced by the underlying mood dimensions of background music. This occurred during a preceding scene where the upcoming course of events was relatively uncertain, and viewers presumably extrapolated a future scenario whose underlying qualities were consistent with the music's affect. This demands more imaginative effort from the viewer and any surprise ending that occurs is relative, not to default knowledge, but to the self-extrapolation. However, despite these differences from previous research, the present results converge with earlier studies by showing that expectancy violations are better remembered than are events that turn out as expected.

Theoretical accounts attempting to explain these effects have typically appealed to attentional and memory-storage factors. These appear to be related issues that derive from the same phenomenon. Because attending is directed over the course of an unfolding event, any information that is anomalous with the perceiver's expectancies stands out and captures attention. In addition, attending becomes more analytical in nature and is directed toward lower level details in an attempt to make sense of what's going on. These two factors together-namely, the surprise of the expectancy violation and increased selective attending-yield a more distinct and elaborate memory code that is highly accessible during retrieval. The latter idea is consistent with Graesser's (1981) schema-copy-plus-tag hypothesis, which claims that any anomalous information is "tagged" onto the memory of an event and is therefore highly retrievable. It also converges with previous research on selective attending. Both Newtson (1973) and Wilder (1978) have shown that atypical actions during a routine behavioral sequence cause a shift from attending to gross units of actions to fine units of detail. Similarly, Brewer and Lichenstein $(1981,1982)$ suggest that determinants of story enjoyment may ultimately relate to attentional mechanisms. When asked to rate which stories are most preferred, subjects consistently select those containing a high degree of surprise, suspense, and curiosity. These authors suggest that enjoyment from such elements may be related to sudden changes in attentional arousalparticularly, sharp rises in arousal immediately followed by arousal reductions. Given that expectancy violations arising from background music yield surprise endings, this too may contribute to the memorability of an episode.

The effects observed in this experiment conflict with those of Spiro (1980), who found no difference in immediaterecall performance as a function of expectany confirmation/violation. To a large extent, this discrepancy may be due to methodological differences. Spiro assessed recall through the number of propositions remembered within a narrative story, whereas recall within the present experiment was measured through the percentage of episodes that were recalled. Given the number and unrelatedness of these scenes, this may have placed a greater demand upon memory facilities, such that expectancy effects were more apt to emerge. The immediate testing procedure used in the present research also did not allow one to evaluate Spiro's primary finding-namely, the higher incidence of constructive memory errors with expectancy violations. Such errors, however, may be apparent after longer reten- 
tion intervals where subjects attempt to reconcile discrepancies between an episode's outcome and the mood of foreshadowing music.

In sum, the interactive effects of mood congruency upon the relative placement of music are assumed to involve different attentional mechanisms. Accompaniment benefits performance through the selective focusing upon mood congruent visual activities, whereas foreshadowing music improves memorability through expectancy violations and selective attending directed toward details of an episode. Although each relies on different cognitive processes, both techniques are equally effective for enhancing the memorability of filmed episodes.

Results from the cued-scene-recognition test reveal further insight into the nature of these underlying memory processes. The most interesting effect to emerge from this task is a significant interaction between mood congruency and music placement. First, consider the foreshadowing condition. Here, scene-recognition performance was above chance but failed to vary as a function of mood congruency. This indicates that scenes preceding an episode's outcome (i.e., the "takeoff' point for expectancy generation) are well remembered, regardless of expectancy confirmation/violation. In addition, the pattern of false recognitions showed that the viewers often confused these scenes with ones that corresponded to an episode's outcome although, again, there were no differential biases due to mood congruency. Notice that these effects appear to conflict with those of the recall task, where it was found that mood-incongruent scenes were better remembered than were mood-congruent ones. The nature of this discrepancy most likely involves an issue of retrievability. That is, the cued-recognition task reveals that foreshadowing music leads to an encoding of both mood-congruent and mood-incongruent episodes. However, some of these filmed events become more accessible in memory than others. Relative to episodes that confirm expectancies, those involving expectancy violation are much more available at the time of retrieval. Given the distinctiveness of their memorial representation, these types of episodes do not require any external memory cue to prompt remembering. Conversely, episodes reflecting expectancy confirmation are less salient in memory and are therefore more difficult to retrieve unless an external cue (i.e., music) is provided. This suggests then that the primary influence of mood congruency is one of retrieval availability. This notion should be further explored with studies that include reaction time as a measure of scene recognition. If mood-incongruent scenes are, in fact, more available for retrieval, then they should be recognized more quickly than mood-congruent ones.

Similar processes also apply to accompanying music. Again, performance on the scene-recognition task was significantly above chance, but false recognitions were equally biased toward relevant and irrelevant scenes from the same episode. Unlike the foreshadowing condition, there were no biases toward "relevant" scenes because these corresponded to scenes immediately preceding an episode's outcome and therefore had no particular sig- nificance. As in the recall task, performance was reduced to the level of chance within the mood-incongruent conditions, but only in the case where negative music accompanied a positive outcome. The reverse pairing-namely, positive music accompanying a negative outcome-yielded a hit rate comparable to that of mood-congruent pairings. The latter condition represents the "ironic contrast" technique in which music is intentionally used by filmmakers to reduce the emotional impact of a scene and/or satirize its connotative meaning. Although this type of episode was poorly recalled and was therefore less salient than moodcongruent scenes, the viewers apparently encoded the ironic association such that a tune was later able to prompt scene recognition. The opposite type of mood-incongruent relation offered no such meaning because the accompanying music is seemingly irrelevant to the scene. The tune was therefore not incorporated into the memory of an episode and performance declined on this task.

Another issue investigated in this experiment concerns the memory of the tunes that influenced the processing of visual scenes. Although incidental memory retention has been observed for various types of background information, including that of human voices (Geiselman \& Bellezza, 1976, 1977), page numbers, and lettering of a given font, color, or orientation (Kolers \& Ostry, 1974; Light \& Berger, 1974; Rothkopf, 1971), evidence suggesting that similar processes occur for background music is less straightforward. In the tune-recognition task, there were no significant effects as a function of the experimental manipulations, and overall hit rate did not deviate from chance performance. Data from the cued-recognition task, however, showed that music could provide effective retrieval cues for recognizing the scene it had originally accompanied. This suggests that some incidental encoding for music occurred but in a form that is strictly dependent upon its relevant scene. Music does not seem to be stored in a holistic form that is independently accessible for retrieval. Instead, its underlying mood dimensions appear to be integrated within the memory of the filmed episode. This is consistent with the notion that viewers rely on the affective expression of music to either generate expectancies about future scenarios (i.e., foreshadowing music) or direct attending toward corresponding aspects of visual activities (i.e., accompaniment). Viewers do not attend to the global attributes that differentiate one tune from another but to those qualities that convey moodrelevant information. Thus, it is only when the originally paired scene is presented that a tune can be recapitulated and thereby re-create the original context of encoding. On the other hand, it should be acknowledged that this phenomenon may be due to the particular methodology of this experiment. Although each tune displayed a unique melodic line and one of many different instruments, melodies in the tune-recognition task were selected on the basis of affect. The structural characteristics of melodies (i.e., tempo, mode, pitch level, and profile of contour change) were used to not only select melodies for positive or negative affect but to match the set of "new" distractor tunes to the set of "old" tunes. The high degree 
of similarity among melodies may therefore account for the chance level of performance in this task. Future studies are needed to investigate this issue and to determine whether the present set of results generalize to a more diverse range of melodies.

The last major finding within this experiment concerns asymmetrical effects due to the particular mood of a tune or an episode's outcome. Across the three memory tasks, positive affect consistently produced higher levels of performance than did negative affect. This finding converges with several other studies investigating the effects of mood upon cognitive activities (e.g., see Isen, 1985, 1987, for a review). Isen has attributed this phenomenon to two related factors. The first is motivational in nature and involves a rational coping strategy. People are simply more motivated to eliminate sad feelings and retain positive feelings that are more enjoyable. Perhaps because of this, Isen also suggests that positive affect may be cognitively structured in a way that is different from negative affect. That is, positive affect may be better integrated into memory and related to a vast network of similar material. It is therefore able to cue a wide range of relevant experiences and events. Negative affect, on the other hand, may be stored in relative isolation from other memories such that it is able to cue only a small range of experiences that are specific to the particular emotion. These two principles may also apply to the present experiment. After viewing a series of filmed episodes, people may be more motivated to retain those scenes resolving to a positive outcome, regardless of whether the scene turns out as expected or is a pleasant surprise. Similarly, results from the tunerecognition and cued-recognition tasks show that positively affected tunes not only are better discriminated than are negatively affected melodies, but they also provide more effective retrieval cues for scene recognition. Such findings support Isen's hypotheses and suggest that positive materials do, in fact, maintain a privileged status in the cognitive system. They also illustrate that mood asymmetries generalize beyond the realm of personal experience and apply to more abstract forms of expression, as found in music and film.

In closing, the research reported here highlights the usefulness of film as a medium in which to investigate certain principles of cognitive psychology. Given that films depict visual stories where characters engage in various activities, they offer a naturalistic setting in which to examine issues of discourse processing and schema-driven behavior. In particular, film not only may be useful for studying various types of inferences as induced by the story's organization or the use of background music, but it may also allow one to assess certain issues of social cognition.

\section{REFERENCES}

BeAR, G., \& Hodun, A. (1975). Implicational principles and the cognition of confirmatory, contradictory, incomplete, and irrelevant information. Journal of Personality \& Social Psychology, 32, 594-604.
Belmore, S., \& Hubbard, M. (1987). The role of advance expectancues in person memory. Joumal of Personality \& Social Psychology, $53,61-70$.

Biederman, I. (1972) Perceiving real-world scenes. Science, 177 , $77-79$

Biederman, I (1981) On the semantics of a glance at a scene. In M. Kubovy \& J Pomerantz (Eds.), Perceptual organization (pp. 213 . 253). Hillsdale, NJ· Erlbaum

BLACK, J., \& BowER, G. (1979). Episodes as chunks in memory Journal of Verbal Learning \& Verbal Behavior, 18, 309-318.

Black, J., Galambos, J., Read, S. (1984). Comprehending stories and social situations. In R. Wyer \& T. Srull (Eds.), Handbook of social cognition (Vol 3, pp. 45-86). Hillsdale, NJ: Erlbaum.

Bobrow, D. Norman, D. (1975). Some principles of memory schemata. In D. Bobrow \& A. Collins (Eds.), Representation and understanding (pp. 131-150). New York: Academic Press.

Boltz, M (1991). Duration judgments of filmed events: Effects due to the relative placement and mood congruency of background music. Unpublished manuscript.

BordWell, D., \& ThOMPSON, K (1979). Film art: An introduction. Reading, MA: Addison-Wesley.

BOWER, G (1976) Experiments on story understanding and recall Quarterly Journal of Experimental Psychology, 28, 511-534.

Bower, G., Black, J , \& TURner, T (1979). Scripts in memory for text. Cognitive Psychology, 11, 177-220.

BREWER, W., \& LICHENSTEIN, E. (1981). Event schemas, story schemas, and story grammars. In J Long \& A. Baddeley (Eds.), Attention and performance (Vol, 9, pp. 363-379). Hillsdale, NJ: Erlbaum.

BREWER, W, Lichenstein, E. (1982). Stories are to entertain: A structural-affect theory of stories. Journal of Pragmatics, 6, 473-486.

Clark, H. (1977). Inferences in comprehension. In D. LaBerge \& S. Samuels (Eds.), Perception and comprehension (pp. 243-263). Hillsdale, NJ, Erlbaum.

Clark, H., Haviland, S (1977) Comprehension and the givennew contract. In $\mathrm{R}$ Freedle (Ed.), Discourse production and comprehension (pp 1-41) Hillsdale, NJ: Erlbaum.

Clynes, M (1983). Expressive microstructure in music. In J. Sundberg (Ed.), Studies of music performance, (Vol. 39, pp. 76-181). Stockholm Royal Swedish Academy of Music, 39, 76-181.

Cosmides, L. (1983). Invariances in the acoustic expression of emotion during speech. Journal of Experimental Psychology: Human Per. ception \& Performance, 9, 864-881.

Crocker, J , Hannah, D., \& Weber, R (1983). Person memory and causal attributions. Journal of Personality \& Social Psychology, 44, $55-66$

Dowling, J, \& HaRwood, D (1986). Music cognition New York: Academic Press.

DUnN, O. (1961). Multiple comparisons among means. Journal of the American Statistical Association, 56, 52-64.

Ekman, P (1978). Facial expression. In A. Siegman \& S. Feldstein (Eds.), Nonverbal behavior \& communication (pp. 97-118). Hillsdale, NJ: Erlbaum.

Ekman, P., Friesen, W (1975). Unmasking the face. Englewood Cliffs, NJ Prentice-Hall.

FrIEDMAN, A. (1979). Framing pictures: The role of knowledge in automatized encoding and memory for gist. Joumal of Experimental Psychology: General, 108, 316-355.

GabRielsSON, A. (1985). Interplay between analysis and synthesis in studies of music performance and music experience. Music Perception, 3, 59-86

Gabrielsson, A. (1989). Timing in music performance and its relations to music experience. In I. Sloboda (Ed.), Generative processes in music: The psychology of performance, improvisation, and composition (pp. 27-51). Oxford: Clarendon.

Geiselman, R. E., \& Bellezza, F. (1976). Long-term memory for speaker's voice and source location. Memory \& Cognition, 4, 483-489.

GeISELMAN, R., \& BeLLEzZA, F. (1977). Incidental retention of speaker's voice. Memory \& Cognition, 5, 658-665.

Gianet1, L. (1982). Understanding movies. Englewood Cliffs, NJ: Prentice Hall. 
GlenN, C. (1978). The role of episodic structure and story length in children's recall of simple stories. Journal of Verbal Learning \& Verbal Behavior, 17, 229-247.

Graesser, A. (1981). Prose comprehension beyond the word. New York: Springer.

GRAESSER, A., \& CLARK, L. (1985). Structures and procedures of implicit knowledge. Norwood, NJ: Ablex.

Graesser, A., Woll, S., Kowalski, D., \& SMTth, D. (1980). Memory for typical and atypical actions in scripted activities. Journal of Experimental Psychology: Human Learning \& Memory, 6, 503515.

HABERLANDT, K. (1980). Story grammars and the reading time of story constituents. Poetics, 9, 99-116.

HANDEL, S. (1989). Listening: An introduction to the perception of auditory events. Cambridge, MA: MIT Press.

HASTIE, R. (1980). Memory for information that confirms or contradicts a personality impression. In R. Hastie, T. Ostrom, E. Ebbessen, R. Wyer, D. Hamilton, \& D. Carlston (Eds.), Person memory: The cognitive basis of social perception (pp. 155-177). Hillsdale, NJ: Erlbaum.

Hastie, R., \& Kumar, P. (1979). Person memory: Personality traits as organizing priciples in memory for behaviors. Journal of Personality \& Social Psychology, 37, 25-38.

Heider, F., \& Simmel, M. (1944). An experimental study of apparent behavior. American Journal of Psychology, 57, 243-259.

HeVNER, K. (1936). Experimental studies of the elements of expression in music. American Journal of Psychology, 48, 248-268.

Hochraus, L. (1972). A table for the calculation of $d^{\prime}$ and $B^{\prime}$. Psychological Bulletin, 77, 375-376.

ISEN, A. (1985). Asymmetry of happiness and sadness in effects on memory in normal college students: Comment on Hasher, Rose, Zacks, Sanft, and Doren. Journal of Experimental Psychology: General, 114, 388-391.

ISEN, A. (1987). Positive affect, cognitive processes, and social behavior. In L. Berkowitz (Ed.), Advances in experimental social psychology (Vol. 20, pp. 203-253). New York: Academic Press.

Keenan, J., Baillet, S., \& Brown, P. (1984). The effects of causal cohesion on comprehension and memory. Journal of Verbal Learning \& Verbal Memory, 23, 115-126.

$\mathrm{KINTSCH}, \mathrm{W}$. (1974). The representation of meaning in memory. Hillsdale, NJ: Erlbaum.

Kintsch, W., \& VAN Dijk, T. (1978). Toward a model of text comprehension and production. Psychological Review, 85, 363-394.

Kolers, P., \& Ostry, D. (1974). Time course of loss of information regarding pattern analyzing operations. Journal of Verbal Learning \& Verbal Behavior, 13, 599-612.

LEVI, D. (1982). The structural determinants of melodic expressive properties. Journal of Phenomenological Psychology, 13, 19-40.

LIGHT, L., \& BERGER, D. (1974). Memory for modality: Within-modality discrimination is not automatic. Journal of Experimental Psychology, $103,854-860$.

LoFrus, G. (1972). Eye fixations and recognition memory for pictures. Cognitive Psychology, 3, 525-551.

LoFTUS, G., BELL, S. (1975). Two types of information in picture memory. Journal of Experimental Psychology: Human Learning \& Memory, 104, 103-113.

Long, D., Golding, J., Graesser, A., \& Clark, L. (1990). Goal, event, and state inferences: An investigation of inference generation during story comprehension. In A. Graesser \& G. Bower (Eds.), The psychology of learning and motivation, Vol. 25. Inferences and text comprehension (pp. 89-102). San Diego, CA: Academic Press.

MAKI, R. H. (1990). Memory for script actions: Effects of relevance and detail expectancy. Memory \& Cognition, 18, 5-14.

MandLer, J. (1978). A code in the node: The use of a story schema in retrieval. Discourse Processes, 1, 14-35.

MANDLER, J., \& JOHNSON, N. (1977). Remembrance of things parsed: Story structure and recall. Cognitive Psychology, 9, 111-151.

Marshall, S., Cohen, A. (1988). Effects of musical soundtracks on attitudes toward animated geometric figures. Music Perception, 6. 95-112.

MCKoON, G., RATCLIFF, R. (1981). The comprehension processes and memory structures involved in instrumental inferences. Journal of Verbal Leaming \& Verbal Behavior, 20, 671-682.

McKoon, G., \& RATCLIF, R. (1986). Inferences about predictable events. Journal of Experimental Psychology: Learning, Memory, \& Cognition, 12, 82-91.

Montepare, J., Goldstein, S., \& Clausen, A. (1987). The identification of emotions from gait information. Joumal of Nonverbal Behavior, 11, 33-42.

Nakamura, G. V., Graesser, A. C., Zimmerman, J. A., \& Riha, J. (1985). Script processing in a natural situation. Memory \& Cognition, 13, 140-144.

NEwTSON, D. (1973). Attribution and the unit of perception of ongoing behavior. Journal of Personality \& Social Psychology, 28, 28-38.

OsGood, C. (1969). On the whys and wherefores of E, P, and A. Journal of Personality \& Social Psychology, 12, 194-199.

Picek, J., Sherman, S., \& Shiffrin, R. (1975). Cognitive organization and coding of social structure. Journal of Personality \& Social Psychology, 31, 758-768.

PluTCHIK, R. (1962). The emotions: Facts, theories, and a new model. New York: Random House.

RJGG, M. (1964). The mood effects of music: A comparison of data from four investigations. Journal of Psychology, 58, 427-438.

RoTHKOPF, E. (1971). Incidental memory for location of information in text. Journal of Verbal Learning \& Verbal Behavior, 10, 608-613.

RusselL, J. (1980). A circumplex model of affect. Journal of Personality \& Social Psychology, 39, 1161-1178.

SCHERER, K. (1979). Acoustical concomitants of emotional dimensions: Judging affect from synthesized tone sequences. In S. Weitz (Ed.), Nonverbal communication (pp. 249-253). New York: Oxford University Press.

SCHLOSBERG, H. (1952). The description of facial expressions in terms of two dimensions. Journal of Experimental Psychology, 44, 229-237.

SHAFFER, H. (1989). Cognition and affect in musical performance. Contemporary Music Review, 4, 381-389.

Singer, M., Revin, R., \& Halldorson, M. (1990). Bridginginferences and enthymemes. In A. Graesser \& G. Bower (Eds.), The psychology of learning and motivation: Vol. 25. Inferences and text comprehension (pp. 35-52). San Diego, CA: Academic Press.

SLOBODA, J. (1985). The musical mind: The cognitive psychology of music. Oxford: Oxford University Press.

Sloman, L., Berridge, M., Homatidis, S., Hunter, D., \& Duck, T. (1982). Gait patterns of depressed patients and normal subjects. American Journal of Psychiatry, 139, 94-97.

Smith, D. A., \& Graesser, A. C. (1981). Memory for actions in scripted activities as a function of typicality, retention interval, and retrieval task. Memory \& Cognition, 9, 550-559.

SPELKE, E. (1979). Exploring audible and visable events in infancy. In A. D. Pick (Ed.), Perception and its development: A tribute to $E$. $J$. Gibson (pp. 221-235). New York: Wiley.

SPIRo, R. (1980). Accomodative reconstruction in prose recall. Journal of Verbal Learning \& Verbal Behavior, 19, 84-95.

SRULL, T. (1981). Person memory: Some tests of associative storage and retrieval models. Journal of Experimental Psychology: Human Learning \& Memory, 7, 440-463.

Srull, T., \& Wyer, R. (1989). Person memory and judgment. Psychological Review, 96, 58-83.

Thayer, J., \& LeVEnSon, R. (1983). Effects of music on psychophysiological responses to a stressful film. Psychomusicology, 3, 44-54.

THORNDYKE, P. (1977). Cognitive structures in comprehension and memory of narrative discourse. Cognitive Psychology, 9, 77-110.

WILDER, D. (1978). Effect of predictability on units of perception and attribution. Personality \& Social Psychology Bulletin, 4, 281-284.

Williams, C., Stevens, K. (1979). Emotions and speech: Some acoustical correlates. In S. Weitz (Ed.), Nonverbal communication (pp. 233-248). New York: Oxford University Press.

\section{NOTE}

1. The use of all filmed material in this experiment conformed to the specifications of the House Report on piracy and counterfeiting amendments (House Report 97-495, pp. 8-9). 
APPENDIX A

Adjective Pairs Used in the Prerating Tasks
1. Happy-Sad
2. Tense-Relaxed
3. Disgusting-Appealing
4. Triumphant-Defeated
5. Serious-Lighthearted
6. Aroused-Calm
7. Bold-Fearful
8. Surprised-Predictable
9. Angry-Agreeable
10. Content-Frustrated
11. Kind-Evil
12. Gentle-Boisterous
13. Suspenseful-Unassuming

\section{APPENDIX B \\ Summary of the Filmed Episodes Used as Experimental Stimuli}

1. A brother and sister, separated in childhood after their parents' deaths, have recently been reunited. After the sister's "welcome home" dinner, the brother takes her upstairs, (foreshadowing, F) blindfolds her, and says he has a surprise for her. The surprise is a large cabinet containing memoriabilia from their grandfather's circus (accompanying, A). (From Cat People, 1982, produced by Universal Pictures, 445 Park Ave., NY, NY 10022)

Positive outcome: Happy, Lighthearted, Kind, Content, Agreeable, Surprising

2. A young man is sitting on a rooftop at night, watching a young woman below as she follows (F) his scribbled clues to a wall mural that he has drawn for her. Uniformed officers suddenly arrive and after hitting her several times, they take her away in an armored car (A). (From Shortstories, episode entitled "Graffitti," 1986, The American Film Institute, 2021 North Western Ave., Los Angeles, CA 90027)

Negative outcome: Sad, Tense, Defeated, Serious, Fearful, Frustrating, Suspenseful, Surprising

3. A woman enters her bedroom and begins to undress as she prepares to go to bed. She suddenly sees a man sitting in the corner of her room $(F)$. As he points a gun at her, he tells her to continue to undress and take down her hair. He then stands, walks toward her, and they embrace (A). Her lover has returned. (From Butch Cassidy and the Sundance Kid, 1969, produced by Twentieth Century Fox, P.O. Box 900, Beverly Hills, CA 90213)

Positive outcome: Happy, Tense, Aroused, Surprising, Suspenseful

4. At home with her husband and daughter, a woman receives a phone call from her physician. The results of her AIDS test have just been received and he schedules an appointment to see her. (F) Later that afternoon, she meets with her physician and discovers that the test results are negative (A). (From Sweet As You Are, 1989, produced by BBC Productions, 630 Fifth Avenue, \#2220, NY, NY 10111)

Positive outcome: Happy, Triumphant, Surprising, Calm

5. A hotel attendant is working in the women's restroom and fantasizes about winning the state lottery. A wealthy customer then walks in complaining about the hotel staff and asks the attendant to remove a stain from her dress. As the attendant is doing so, the customer accidentally ruins the attendant's lottery ticket by spilling water on it. (F) Later, after zipping up the cus- tomer's dress, the attendant strangles her and leaves her on the floor of the restroom (A). (From Shortstories, episode entitled "Greed: Pay To Play," 1986, ZDF Productions, Germany) Negative outcome: Tense, Serious, Angry, Disgusting, Evil, Suspenseful

6. A man is at home, quietly celebrating his own birthday, when two men knock on his door. They identify themselves as federal agents and say they have a warrant for his arrest for a murder that he committed 20 years ago. Despite his protests of innocence and attempts by his lawyer to free him, the federal agents force him into their car and drive away. They soon arrive at a hotel $(F)$ where the agents' supervising officer is presumably waiting. After opening the door to the hotel room, the man is met by his wife and a surprise birthday party (A). (From Alfred Hitchcock Presents, episode entitled "Happy Birthday," 1986, Universal Television, Universal City, CA 91608) Positive outcome: Happy, Triumphant, Lighthearted, Surprising, Suspenseful

7. After participating in an aerobics class, a woman returns home and enters her kitchen. (F) As she drinks a glass of orange juice, she is attacked from behind and subsequently raped (A). (From Alfred Hitchcock Presents, episode entitled "Revenge," 1985. Universal Television)

Negative outcome: Sad, Tense, Disgusting, Defeated, Serious, Aroused, Fearful, Surprising, Angry, Frustrated, Evil, Suspenseful

8. A young man attempts to break into a classified government computer file containing data on genetically engineered people. He suceeds, (F) but finds his own name on the list (A). (From Shortstories, episode entitled "Hacker John," 1986, Atlantis Films, Cinevillage, 65 Heward Ave., Toronto, Ontario, Canada M4M 2T5)

Negative outcome: Tense, Serious, Aroused, Bold, Surprising, Suspenseful

9. After buying a prescription from her local drugstore, a woman is walking home and thinks she is being followed by a man. The man later knocks on the door of her apartment $(F)$ and after showing her his ID, she discovers that he is merely the electrician hired to do some work on the dance floor downstairs (A). (From Alfred Hitchcock Presents, episode entitled "Mirror, Mirror," 1985, Universal Television)

Positive outcome: Tense, Suspenseful, Aroused, Fearful

10. A man and a woman, divorced from one another several years ago, are on his houseboat near a marina. They reconcile and decide to live together on the boat. She borrows his car (F) to get some of her belongings, but when she turns the ignition key, the car blows up and she is killed (A). (From Alfred Hitchcock Presents, episode entitled "Full Disclosure," 1985, Universal Television)

Negative outcome: Sad, Disgusting, Defeated, Serious, Aroused, Angry, Surprising

11. A mob is trying to overnun a small town jail in an attempt to capture one of the prisoners who is suspected of killing a young girl. The suspected prisoner escapes and forces another prisoner to change clothes (identities) with him. The mob is in the process of lynching $(\mathrm{F})$ the innocent prisoner when a police helicopter comes to his rescue (A). (From Alfred Hitchcock Presents, episode entitled "Incident From a Small Town Jail," 1985, Universal Television)

Positive outcome: Tense, Triumphant, Serious, Boisterous, Suspenseful, Surprising

12. A woman is delivering some groceries to her brother. As she crosses his lawn, several small explosives go off around her. (F) The brother emerges from the bushes, laughing, and explains 
that the explosions were harmless (A). He was merely entertaining himself by scaring his sister. (From The Hitchhiker, episode entitled "Hootch," 1987, Lewis Chesler Productions, 7060 Hollywood Blvd., Suite 614, Hollywood, CA 90028)

Positive outcome: Surprising, Aroused, Suspenseful, Boisterous

13. Two policemen chase a woman, first in their car and later on foot. After catching her, they ask several questions about her brother who's hiding from the law. (F) She refuses to answer and is severely beaten by the police (A). (From Shortstories, episode entitled "Face To Face," 1986, Ron Rapiel, 13929 Marquesas Way, \#312, Marina del Ray, CA 90292)

Negative outcome: Tense, Serious, Evil, Suspenseful, Angry, Aroused

14. A young woman enters a crowded restaurant and is seated at a table. She then places a bag under the table and immediately walks out of the restaurant. (F) As she and a companion drive away in their car, the restaurant is "leveled" by a massive explosion (A). (From Exposed, 1983, produced by MGMUA, $10000 \mathrm{~W}$. Washington Blvd., Culver City, CA, 90232) Negative outcome: Sad, Tense, Disgusting, Evil, Suspenseful, Serious, Aroused, Surprising

15. A deaf boy hires a mob hitman to kill his father. After the father arrives home, the hitman emerges from the bedroom closet and (F) approaches the boy from behind. He then places both hands around the boy's neck as if preparing to strangle him. Instead, he turns the boy around and they embrace (A). (From Alfred Hitchcock Presents, episode entitled "A Very Happy Ending,"' 1986, Universal Television)

Positive outcome: Tense, Serious, Aroused, Suspenseful, Surprising

16. A female inmate "cons" a prison attendant into helping her escape. He agrees to bury her with the next inmate who dies and then later dig her up from the cemetery outside of town. A few nights later, she crawls into a casket whose corpse is subsequently buried. After waiting several hours to be dug up, (F) she finally lights a match in the casket and discovers that the corpse is the prison attendant himself (A). (From Alfred Hitchcock Presents, episode entitled "Final Escape," 1985, Universal Television)

Negative outcome: Sad, Tense, Disgusting, Defeated, Angry, Suspenseful, Surprising, Fearful

(Manuscript received January 10, 1991; revision accepted for publication April 9,1991 .)

\title{
Notices and Announcements
}

\author{
Members of Underrepresented Groups: \\ Reviewers for Journal Manuscripts Wanted
}

On behalf of Memory \& Cognition and Psychonomic Society Publications, I invite you to contact me if you are interested in reviewing manuscripts for Memory \& Cognition. Please send a letter and a copy of your curriculum vita to me at the following address: Memory \& Cognition, Department of Psychology, Indiana University, Bloomington, Indiana 47405. The letter or the vita should contain your complete address (including an electronic mail address if one is available), telephone number, and area(s) of expertise. Our reviewers have published articles in peer-reviewed journals, a standard prerequisite for being selected as a reviewer.

Please note that reviewing manuscripts takes time and must be completed quickly. If you are asked to review a manuscript, you will be expected to provide a thorough and prompt review.

Margaret Jean Intons-Peterson Editor 